\title{
Introduction of Innovations into the Traditional Teaching of Construction and Building Materials
}

\author{
Encarnación Reyes, Ph.D., P.E. ${ }^{1}$; and Jaime C. Gálvez, Ph.D., P.E. ${ }^{2}$
}

\begin{abstract}
The traditional teaching methods used for training civil engineers are currently being called into question as a result of the new knowledge and skills now required by the labor market. In addition, the European Higher Education Area is requesting that students be given a greater say in their learning. In the subject called Construction and Building Materials at the Civil Engineering School of the Universidad Politécnica de Madrid, a path was set three academic years ago to lead to an improvement in traditional teaching by introducing active methodologies. The innovations are based on cooperative learning, new technologies, and continuous assessment. The writers' proposal is to offer their experience as a contribution to the debate on how students can be encouraged to acquire the skills currently demanded from a civil engineer, though not overlooking solid, top-quality training. From the outcomes obtained, it can be concluded that using new teaching techniques to supplement a traditional approach provides more opportunities for students to learn while boosting their motivation. In our case, the introduction of these changes has resulted in an increased pass rate of $29 \%$ on average, when such a figure is considered in the light of the mean value of passes during the last decade.
\end{abstract}

CE Database subject headings: Construction materials; Engineering education; Undergraduate study; Teaching methods; Innovation.

Author keywords: Construction materials; Engineering education; Undergraduate study; Teaching methods.

\section{Introduction}

Civil engineering education in Spain, except the school of the Universidad Politécnica de Madrid (UPM), where the old syllabus is currently in force, has undergone important changes in recent years. At present, Spanish universities in general are required to face up to new changes in order to attain European higher education uniformity, which ensures educational quality as well as the mobility of professionals (European Ministers of Education 1999). As a result, the schools of civil engineering, and in this case, we also include the UPM, are in the process of change. Also, for several years, various writers have highlighted the need to bring about a transformation in civil engineering education to adapt it in a more suitable form to the new requirements of the professional career (Fólder 1996). One of the main reasons is that recent decades have seen a technological revolution of such a significant scale that its consequences on future civil engineers are inevitable. The labor market is at present demanding engineers in possession of new skills and knowledge, which means the training of students needs to improve if they are to be endowed with the competencies required to satisfy such requirements.

\footnotetext{
${ }^{1}$ Associate Professor, Dept. of Civil Engineering: Construction, School of Civil Engineering, Universidad Politécnica de Madrid, C/Profesor Aranguren s/n, 28040 Madrid, Spain (corresponding author). E-mail: ereyes@caminos.upm.es

${ }^{2}$ Full Professor, Dept. of Civil Engineering: Construction, School of Civil Engineering, Universidad Politécnica de Madrid, C/Profesor Aranguren s/n, 28040 Madrid, Spain. E-mail: jcgalvez@caminos.upm.es
}

At present, the construction sector has become increasingly important in the economy of every country (Martínez Montes et al. 2007). The complexity of construction projects, with largescale buildings and structures, the use of new construction methods and materials, together with the need to optimize their inservice performance and durability over time, all have a bearing on different aspects that need to be taken into account when training future engineers. In the first place, it is essential to be able to work as part of a group so that specialists in different disciplines can be effectively integrated. Another key point is that of being skilled in knowledge management (Salazar 2003), both as to understanding and handling the information provided by new technologies and the sharing of the knowledge acquired within the framework of cooperative work. Finally, the importance of making students fully aware of environmental issues should be underlined, as this is a basic foundation on which future engineers can implement sustainable development (Kelly 2008). Therefore, studying materials durability as well as their environmental impact and recycling, are indispensable aspects of the training of future civil engineers and fundamental to a proper assimilation of the vast field of knowledge from other subjects.

All such determining factors, among others, require an evolution in teaching techniques at a university level in order to attain the new goals pursued in the education of new civil engineers (Alexander et al. 1996; Stevens 2004). Moreover, universities need to demonstrate their worth in terms of accreditation through agencies such as the Accreditation Board for Engineering and Technology in the United States and the National Agency for Quality Assessment and Accreditation in Spain (Aparicio and Ruiz-Terán 2007). To this end, they must satisfy a set of appropriate criteria for transmitting job skills that are important in civil engineering, such as, for example, the ability to communicate, work in a team, and possess a comprehensive understanding of the relationship between engineering and society (Quinn and Al- 
bano 2008). At this point, it is important to underline the fundamental role of the teaching staff, as they are the players who can acquire the ability to facilitate a new, more student-centered concept of learning that teaches students how to learn. Hence, it is necessary not only to assess their knowledge and training but also their attitudes toward such change. It is essential for the teaching staff to be aware of the ins and outs of the different ways of learning, as well as different learning techniques, so that they can make appropriate use of them to encourage autonomous as well as cooperative learning in students. In our opinion, all this requires adequate teacher training that is enriched by the experience of both teaching staff and others when applying the new teachinglearning methods.

The study of the Construction and Building Materials is of great importance in civil engineering education. It is easy to see the close relationship between civil engineering and the needs of society, the economy and the environment, as well as the permanent use of materials taken from nature for construction purposes. Therefore, civil engineers must design and construct public works and buildings of different kinds, ensuring functionality, integrity and durability while bearing in mind all the technical, economic, aesthetic, and environmental factors and, at the same time considering all the building and construction materials available from each of these aspects as they are present at every stage of the project. None of the constructions planned, constructed, preserved, and run by a civil engineer (dams, canals, ports, bridges, tunnels, roads, and railways, among others) are conceivable without the material as a physical substructure, and without a proper knowledge of its properties, how it can be handled on site, its behavior, and durability.

The intention behind our writing this paper is precisely to contribute our own experience in teaching Construction and Building Materials to the discussion on how to integrate the teaching of technical skills into the quality university education required by future professional civil engineers. In what is to follow, we shall describe the introduction of some innovations into teaching and assessment methods in the subject of Construction and Building Materials, as a supplement to traditional methodologies which began to be implemented in the 2006-2007 course with the support of three annual educational innovation projects at the UPM. Major basic aspects of these changes are the use of group work, continuous assessment with three midterm examinations during the course, and new technologies, mainly through the moodle (http://moodle.org/) platform and audiovisual resources. Over the past three academic years, following the introduction of active teaching techniques, the percentage of students passing over students enrolled has risen on average by $29 \%$, reaching a current figure of $75 \%$. In the last decade, this increment has represented an increase of $63 \%$ on the average value adopted in the years prior to $2006-2007$.

\section{Teaching Construction and Building Materials at the UPM Civil Engineering School}

The syllabus in force at the Civil Engineering School of the UPM was approved by Ministerial Order on June 21, 1983, slightly modifying the previous $1964 / 1975$ version. This is intended for six academic years (bachelor and master integrated degrees), with the first four being common to all and the last two being specializations. Fig. 1 illustrates the main subjects of this syllabus. There are four possible branches: foundations and structures, transport, town and country planning, and hydraulics and energy. However, contrary to what might first appear, given that there are certain specializations, this syllabus may be considered as one of a general nature. The objective of the plan is to produce future civil engineers with solid training and a sound ability to adapt to the changing and specialized technological world in which they will work. The downside is that students have a large number of hours in class and practical work, as well as a very heavy personal workload. The average duration of studies at the Civil Engineering School of the UPM is in excess of 8 years (Gálvez 2003; Universidad Politécnica de Madrid 2006). To complete the description of the educational context in which the subject of construction and building materials is taught at the Civil Engineering School of the UPM, Tables 1 and 2 reveal, respectively, important details of the school curriculum and student learning procedures, and statistical data concerning the particular subject. The data collected in these tables are somewhat disappointing and give an idea of the challenging nature of the Civil Engineering degree taught at the school. Given that this data are quite daunting, student motivation remains a constant challenge.

As already mentioned in the introduction, the circumstances of the school are about to change in the very near future as a result of the reform of syllabus aimed at harmonizing university degrees in the European education area. This plan to build a European higher education area (EHEA) was conceived with the purpose of driving European cooperation and ensuring the quality of higher education, at the same time as promoting career opportunities and international competitiveness (European Ministers of Education 1999). It was also hoped that some of the repercussions would be an enhancement of social cohesion, equal opportunities, and quality of life (European Ministers of Education 2001). For this change, there needs to be a conceptual rethink of the training and learning models in terms of competencies and not objectives as has been the case up to now. This means that the plans, models, and resources used in the teaching-learning process of higher education need to be changed. In the case of our civil engineering school, considerable change and effort will be required, both institutional and individual, by teaching staff in a process of change that has all the signs of being challenging. At this point, it is important to emphasize the fundamental role of the teaching staff, given that they are the players who can acquire the ability to facilitate a new more student-centered concept of learning.

Construction and Building Materials is currently a core subject worth 15 traditional credits (a traditional credit is equivalent to ten hours of attendance in class) (Universidad Politécnica de Madrid 2006) that is taught on the second year of the degree as an annual subject. At the Civil Engineering School at the UPM, this is linked to the area of construction engineering. It is a technicalscientific subject that serves as a bridge between more scientific first course subjects (such as mathematics, chemistry, and physics) and the more technological subjects of later modules (materials strength, theory of structures, concrete, and prestressed concrete, among others) (Gálvez 2003). In such a way, in Construction and Building Materials, the knowledge acquired in the first year is applied to the study and understanding of building and construction materials. Moreover, it provides a basis for incorporating all the usual aspects of technology to be found in engineering practice: the application of specific standards and calculation methods. In addition, many other subjects forming part of the syllabus, with their different specializations have Construction and Building Materials as their foundation and are looked at from different angles (see Fig. 1 for details). For instance, the organizational aspects of building construction work that are related to construction and building materials are studied in the subject 


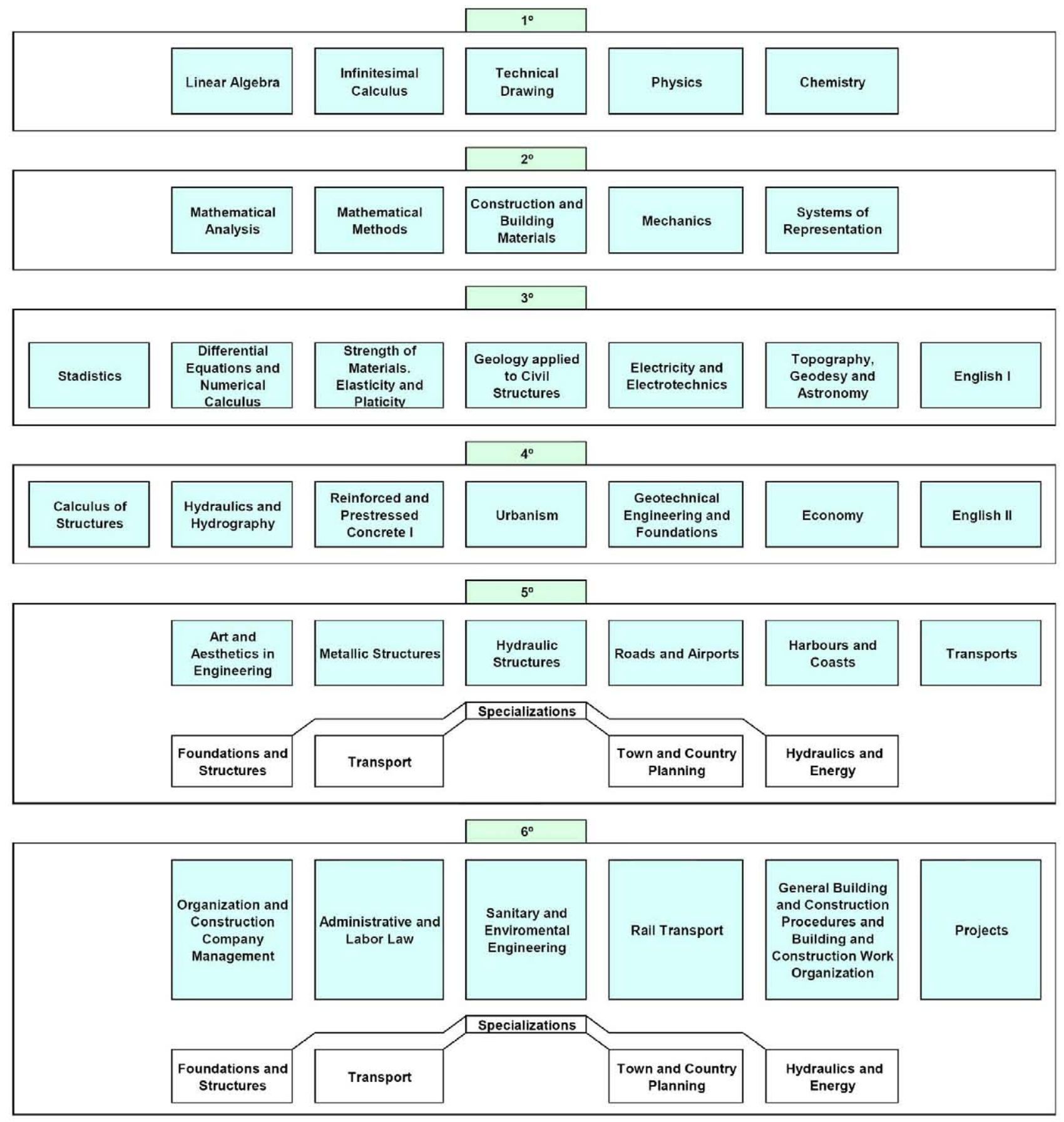

Fig. 1. Civil engineering degree syllabus at the UPM

called General Building and Construction Procedures and Building and Construction Work Organization. The economic aspect is studied in subjects like Economics and Organization and Construction Company Management. Legal aspects of construction and building materials are also included in the syllabus through the study of regulations on materials, hygiene and safety at work and labor legislation, in subjects like Administrative and Labor Law, as well as other technological subjects. All these give some ideas of the importance of construction and building materials for civil engineers, for their training as well as their everyday work.

On academic years prior to 2006-2007, teaching the subject was based on purely traditional teaching methods and assessment, with lectures and two exams every 4 months during the course and then a final examination. In order to address the already men- tioned changes affecting the civil engineering profession, and to enter gradually into the spirit of the new European Credits Transfer System credits, since the 2006-2007 course, some innovations in teaching and assessment methods have been introduced with the support of three annual educational innovation projects at the UPM. Major basic aspects of these changes are cooperative learning, group work, continuous assessment with three midterm examinations during the course, and the use of new technologies, through the moodle platform and audiovisual resources. Table 2 shows important details of the situation of the students enrolled on the subject in recent courses.

The changes were introduced with a model that we planned as being progressive. That is to say, during each academic year, we collect feedback on the experience acquired with the alternative 
Table 1. General Statistics of the Civil Engineering Degree Taught at the UPM

\begin{tabular}{lc}
\hline Important aspects of the educational context & Average \\
\hline Number of students admitted at the school each year & 354 \\
Percentage of students dropping out after 1 year & 35 \\
Percentage of students dropping out for failing to pass three & 11
\end{tabular}

subjects in their first 2 years

Percentage of students who complete the first and second years degree in their first 2 years

Percentage of students attending lectures at university in the first two academic years ${ }^{\mathrm{a}}$

Percentage of students attending extra classes outside university in the first two academic years or who have some relationship with them (e.g., with notes of the academies) $)^{\mathrm{a}}$

Number of students graduating each year

Percentage of students completing their studies in 6 years (over graduate students)

Percentage of students completing their studies in 7 years (over graduate students)

Percentage of students completing their studies in 8 years

(over graduate students)

Percentage of students completing their studies in 9 years

(over graduate students)

Percentage of students completing their studies in 10 or more years (over graduate students)

${ }^{\mathrm{a}}$ Estimates from data through surveys of students which have a low participation rate ( $16 \%$ on average).

teaching techniques, correcting any areas that are lacking and strengthening the positive ones, thereby improving students' achievement and acquisition of knowledge and skills, while giving the subject a more technological approach which we consider essential for training engineering students (Ruiz et al. 2001). Of course, in later stages, these actions must evolve to adapt to the new syllabus framework once it is known.

\section{Motivating Students}

It is well known throughout the teaching profession that student motivation in the face of academic work, both inside and outside the classroom, is one of the most determining factors in the learning process. Motivated students apply themselves to work sooner, concentrate more on what they are doing, are more persistent and generally devote more time and effort to the task, than unmotivated students. Therefore, we understand that this will be a major

Table 2. Statistical Data of the Subject of Construction and Building Materials

\begin{tabular}{lc}
\hline Situation of the students enrolled in the subject & Average \\
\hline $\begin{array}{l}\text { Percentage of students who still have not passed all } \\
\text { first-year subjects }\end{array}$ & 95 \\
$\begin{array}{l}\text { Percentage of students who pass the subject the first year } \\
\text { (since 2006-2007 course) }\end{array}$ & 73 \\
$\begin{array}{l}\text { Percentage of students who pass the subject the second year } \\
\text { (since 2006-2007 course) }\end{array}$ & 21 \\
$\begin{array}{l}\text { Percentage of students who pass the subject the third and } \\
\text { subsequent years (since 2006-2007 course) }\end{array}$ & 6 \\
$\begin{array}{l}\text { Percentage of students who have taken part in some of the } \\
\text { proposed innovations suggested in the subject }\end{array}$ & 82 \\
\hline
\end{tabular}

issue for encouraging student interest in the subject. In order to enhance motivation and learning strategies, we need to examine and evaluate our teaching method models regarding their effect on student motivation by collecting relevant feedback. The writers have decided to devote this section to reviewing the most important aspects of student motivation, as it is one of the most influential basic factors of the innovations incorporated into the area of construction and building materials.

After a year studying at the Civil Engineering School of the UPM, second academic year students have now been initiated into the habit of studying, as well as the skills of synthesis and analysis, both fundamental tools for making individual progress from the teaching received (Gálvez 2003). However, it is usually necessary for these habits to be already developed and established. This should be borne in mind when considering the type of teaching and teaching methodologies for the subject. At this level, a student's critical reasoning is still very limited. It is, therefore, essential to encourage work habits, synthesis, analysis, and a certain critical ability in the course of the subject, and be aware that all should be performed in a way that motivates the student to take full advantage of the class, and to the ensuing satisfaction of both student and tutor (Gálvez 2003).

Student motivation is directly related to personal and professional interests. Numerous pieces of research have attempted to demonstrate the effect of different types of student motivation on learning, such as personal factors, on which an adequate motivation depends (Covington 2000; Ryan and Deci 2000; Tapia 2007; Sánchez 2007). Taking the results of these works and the different classifications that can be made depending on the writer followed, we listed the interests of second course students at three different levels (Gálvez 2003)

1. Those only wanting to pass the subject. In the context of the Civil Engineering School of the UPM, this is the most usual level, due to the traditionally demanding nature of the first 2 years, with a high university drop-out rate. This level of motivation is regardless of course content. However, actions that can be regarded by students as facilities for passing the subject will serve as an incentive for study. One immediate consequence is that students will devote more time to the subject if they see it as within reach, acquiring an improved learning of the subject matter. It is also more likely that this will lead to the circumstances required for students to attain higher levels of motivation, other than just wanting to achieve a pass grade.

2. A desire to accumulate useful knowledge for their future career, which students still see as a distant future, though one which excites them. Many researchers have studied this aspect (Covington 2000; Ryan and Deci 2000; Tapia 2007), and have reached the conclusion that university students are interested in acquiring knowledge that is clearly seen to be relevant and useful for the achievement of future goals in the short-, medium-, and even long-term. As Construction and Building Materials is the first subject directly related to the civil engineering profession, students are attracted by everything that has a real and immediate use. Of course, it should not be forgotten that students a priori are not fully aware of the practical use of the subject, which means that making it known is one of the major tasks of the teaching staff. It is therefore advisable to link, whenever possible, theory and problems to actual practical attractive work situations.

3. An interest in looking more deeply into the specific knowledge of construction and building materials. This last level of interest is only found in a small group of particularly predis- 
posed students. In spite of the very few students being interested, this must be taken into account so as not to discourage them and cause them to fall to lower levels of academic attainment. This group of students comprises a potential source of future researchers in the area of construction engineering and should be given the greatest possible support. This is easier if the subject has internal coherence, so that students to be able to assimilate the general scheme of knowledge set out, together with (of no less importance) the gaps that need to be studied and subsequently filled.

Teaching and assessment methodologies need to address three levels of student motivation if they are to "attract" the student and to optimize achievement, regardless of academic interests. Another important question to bear in mind when considering the supplementary teaching-learning tools to be used to satisfy students is that, at present, students are highly proficient in computing, something that should be exploited to the full. Such students have generally developed good skills for working with computers and programs, often due to pastimes, and are quite familiar with net searches to find information and the use of the available resources. For this reason, since the 2007-2008 academic year, a subject area has been opened on the moodle platform where students can access a wide range of information on the field, provided throughout the year for self-study and self-assessment. As more material has been uploaded, the platform has been fairly widely used and has become useful as a communication tool, particularly between the teaching staff and students, and among the latter themselves. In particular, self-assessment questionnaires have proved particularly popular for preparation for examinations.

Our experience reveals that in the earlier parts of the degree students find working on their own uncomfortable, which leads to a certain rejection as it requires them to think and show personal initiative. Students are reluctant to accept this autonomy which, nonetheless, is needed for them to progress smoothly in their university studies. In addition, they are also reluctant to add to their class explanations by using reference books, preferring printed handouts and literature with all the problems solved, which should preferably include the examinations of previous years as basic study material. In addition, there is the age-old problem of poor attendance rates. There is a clear difference in the number of students enrolled in the modules of the earlier parts of degree courses and the numbers attending classes (see Table 1 for details). The major cause is that students who reject working on their own, as we have mentioned, find ways of avoiding doing so by using other channels where they can obtain intensive and/or extensive courses on how to tackle "standard" problems or procedures. This is a serious problem, not only because classes are missed but also because it leads students into a nonadvisable way of working which deprives them of personal study and the need to think under the guidance of a university tutor, which we consider to be an essential element of the higher education learning experience. However, combating such a tendency is a rather significant challenge, as current students enter university with considerable gaps in their knowledge, and also because there is a large educational market that revolves around the degrees being offered to students that has methods of working which are unavailable at the school due to the basic principles and objectives on which it is founded: the substitution of personal work and the application of reasoning to study by using simple manuals on how to apply solutions to standard problems. To this, the further difficulty of student concern for the high levels of failure over the first 2 years of the degree must be added.
In the light of all such circumstances, we have approached the subject of Construction and Building Materials with a series of methodological and assessment innovations, bearing in mind the interaction between the goals pursued by students in their academic work and the preferred ways to tackle such work. The empirical evidence collected from the works examined (Covington 2000; Ryan and Deci 2000; Tapia 2007) reveals the effectiveness of proceeding along the lines of this model, if the aim is to boost motivation and the approach to learning with adequate strategies. We therefore hope to continue to obtain the positive results we have already achieved by taking this path. Obviously, if improvement is to be had, it is necessary to reflect and review systematically the results, as well as what we teachers actually do in class, to move forward. To our satisfaction we have seen how over the last 3 years, attendance at classes has risen to $78 \%$ on average, and also-particularly in the case of the subject of Construction and Building Materials-extracurricular classes taught outside the university have almost ceased to exist. At present, the only link left to the students enrolled in this subject with such academies is the circulation of old class notes taken by students who attended their classes in previous years. According to data from surveys carried out of the enrolled students, around $27 \%$ have a copy of these notes.

\section{Innovation in Construction and Building Materials}

Construction and Building Materials is the first subject of the current syllabus taken by students that is truly directly applied to civil engineering. A knowledge of materials, how they relate to the form of the structure, their properties, uses and on-site handling, as well as their durability, environmental impact, and recycling, as previously stated, are indispensable aspects in the training of future civil engineers and essential for effectively assimilating the knowledge from other subjects. Taking all this into account, as well as the guide marked out by the syllabus, the following objectives have been set for the subject of Construction and Building Materials, with a distinction being made between those that refer to the competencies to be acquired, which according to Bologna form, the basis for reformulating training and learning models, and those that only refer to the knowledge acquired in the course of the subject. Therefore, this needs to be considered when planning the course.

\section{Competence Objectives}

Studying Construction and Building Materials requires students to acquire three types of competencies according to the recommendations given by the university, which are listed in Table 3: those that are subject-specific (specific competence objectives), those referring to the use of specific elements for the acquisition of knowledge (instrumental competence objectives), and those referring to the way of acquisition (methodological competence objectives).

\section{General Cognitive Objectives}

The subject should provide students with an overall vision of construction and building materials, their applications and how they relate to the structural form and the way to build it. This vision is highly important for training students because it enables them to relate the course content of this subject with that of other more technological subjects to be found in higher courses, 
Table 3. Competence Objectives in Construction and Building Materials

\begin{tabular}{lll}
\hline Specific & \multicolumn{1}{c}{ Instrumental } & \multicolumn{1}{c}{ Methodological } \\
\hline $\begin{array}{l}\text { Critical reasoning } \\
\text { Approaching and solving problems }\end{array}$ & $\begin{array}{l}\text { Ability for analysis and synthesis } \\
\text { Ability to manage information } \\
\text { Ability to organize and plan } \\
\text { Oral and written communication } \\
\text { appropriate to the study environment }\end{array}$ & Ability to adapt to new situations \\
Verifying hypotheses & Autonomous learning \\
Critical analysis of results & Ability to apply knowledge to practice \\
Knowledge and application of regulations & Problem solving & Motivation toward quality \\
Planning laboratory experiments & Decision making & Sensitivity to environmental issues \\
Obtaining experimental data & Bibliographic searches & Awareness of on-site decisions \\
Writing and interpreting technical & Compiling information & Knowledge and application of \\
documentation & & mandatory regulations in force
\end{tabular}

thereby enabling them to understand and apply technological regulations and recommendations with the required judgment and critical reasoning. Here, we would like to point out that in Construction and Building Materials we are unable to support any simplistic approach to technology that would reduce it to a mere presentation of the regulations, codes and recommendations applicable to the materials used for building and construction and their features. This would fail to satisfy expectations of what constitutes a good basic training for an engineer. One of the goals of the general education of the civil engineer must be to develop an awareness of the importance of a general knowledge of engineering practice in future graduates, as well as the need to enhance and update this knowledge throughout life (Kelly 2008). The teaching aims referring to the knowledge acquired by students of this subject are therefore channeled toward providing a scientific and technical learning. These are listed below

1. Knowledge of the materials used by civil engineers in the course of their work;

2. Knowledge the properties, uses, ways of working, and onsite handling of (and how) the materials used by civil engineers are related to the structural form;

3. Knowledge of the standards and quality control rules for construction and building materials;

4. Ability to select the most appropriate materials for each use, identifying needs and evaluating the properties of the materials using calculation models, laws, and general principles of physics and chemistry;

5. Ability to relate structural typology, the material to be used and the construction method;

6. Knowledge of and ability to analyze the main physicalchemical processes that change the behavior of materials throughout their life and influence durability;

7. Ability to determine material properties experimentally;

8. Knowledge of and ability to use the regulatory principles that allow controlling and ensuring material quality, as well as its on-site handling; and

9. Ability to analyze and assess the influence on the environment of material life cycles: manufacture, use and elimination, and/or recycling.

\section{Using Cooperative Learning}

When designing the teaching-learning methods, we have considered the determining factors of the new requirements of civil engineer training mentioned in the introduction, as well as the teaching aims. These are directly related to the profile and cir- cumstances of the average student taking the module, set out in the section "Motivating Students" of this paper. In addition, we have attempted to draw up a realistic project while not forgetting the circumstances and context in which teaching takes place, as well as the limitations of both human and material resources, not only in absolute terms but also in terms relative to the number of students.

Referring back to that stated in the section on student motivation, three levels of interest need to be addressed. The lowest level comprising students who simply wish to pass requires measures aimed at forms of assessment. In principle, such a student has no special interest in learning, which means they will only keep up with the subject if they have to work with the material needed to obtain a pass. To address this factor, we have introduced cooperative learning into the subject to solve problems in class, and to prepare longer open-ended pieces of work to be carried out throughout a term, designed in line with course aims and in such a way that their completion will contribute in an important way to gaining a pass. The problems set in class are designed to be solved in informal groups of three to four students in around 10-20 min. Cooperative learning encourages students to learn from one another and has been shown to be more effective than competitive or individual learning in achieving and developing greater critical reasoning ability and synthesis and analytical skills, promoting a positive attitude to study, improving communication skills, and boosting self-confidence (Johnson 1999; Aparicio and Ruiz-Terán 2007). At least one of these group problems is set every week and assessed, giving every group member the same mark. The mark obtained forms part of the student overall class mark added to the each of the three examination grades per term set every year. They account for $10 \%$ of the mark of each examination for each term. In addition, more complex group work is set that requires an in-depth study of some aspect of construction and building materials, done out of class. In this case, any student can be part of the group. Each group comprises three or four members. The objective is that students who undergo continuous assessment, apart from passing an examination, have to work with construction and building materials under the supervision and direction of a teacher; they can form part of the work groups regardless of whether or not they attend class. By setting this more extensive work, it is hoped that students will be able to identify the knowledge they possess, what they need to know and where to find information, at the same time as learning to make group decisions and present and sustain their ideas, thereby developing their communication skills. This work has to be presented in the presence of their fellow students. On the one hand, it develops their ability to express their ideas 
orally; on the other, as they have to explain their results to others, it promotes a clarification of knowledge in that it is transmitted, which in turn leads to enhanced learning by the student displaying work to others (Elshorbagy and Schonwetter 2002).

Our experience is that the number of students in class has risen during these last three academic years where cooperative learning has been included in teaching, given that "keeping up" with the subject and continuous assessment both help students to do the self-study required to pass. For some, this has also produced an opportunity to raise their interest in the subject.

A desire to accumulate knowledge useful for a career is the second level of motivation. To address this desire, the subject needs to be approached in such a way that students are aware that knowledge passed on to them is of valuable help, if not essential, to obtain a high level post. The writers believe this to be possible in practically every topic taught in theory classes, if studies are organized in a way that most theoretical work is not isolated from practice. To this end, it is essential that the interest of these students in the topic examined or problem approached at the start of a class be awakened. The relevance and use of acquiring the knowledge or skills presented as learning aims should also be pointed out. In this sense, it might be of relevance to present a previous example that sets a real problem that (insofar as is possible) is relevant and up-to-date. This should show that the theory to be developed is needed to solve the problem. New or surprising information can also be presented that breaks with previous student ideas and serves to demonstrate the potential usefulness of what is about to be learned. Regarding the problems proposed for the subject, we feel it would be useful to write the principles in such a way that the steps and calculations are similar to what a professional engineer would do. We use such a technique in the majority of the exercises set in problem-solving classes, including those to be done cooperatively. Similarly, interesting is the practical point of view of prestigious professionals, for which reason two conferences are organized every year to deal with the most up-to-date construction and building materials-related topics: such as new materials and singular applications, among others. Finally, to illustrate the use of the knowledge taught, technical videos are shown that link professional practice to the teaching received in the classroom and laboratory.

The highest level of motivation is the most difficult to satisfy. An interest in entering in depth into specific aspects of construction and building materials requires a more complex and subjective response. The subject must be taught so that students can perceive its global architecture, while being able to sense the weak points and possible lines that can be developed and examined in more detail. However, it is difficult to find the balance between the presentation of solidly consolidated knowledge and an explanation of problems still open to research. In essence, the subject should not be explained as a closed field in order to not disappoint the most intellectually gifted students. However, explaining too many of the gaps in knowledge will have a negative effect on the medium level students who only seek in the subject useful knowledge for their career. To gain a suitable balance, we believe it would be of benefit to emphasize the advances and contributions of the subject, as well as show its limitations, as possible steps forward rather than merely defects.

To include all the above, as well as achieve the objectives set in the teaching plan, the tasks organized in the subject are the following:

1. Master classes (lectures) backed up by audio-visual resources to teach basic theory with a highly practical approach, and devoting part of the classes to continuous assessment. To carry this out, some time should be set aside (approximately 10 min every 3 weeks) for raising and answering questions on the topics presented. It is also important that student participation in these classes be encouraged, though always of a voluntary nature. Moreover, in such lectures, students are provided with the knowledge required to complete the work set throughout the course, such as, for example, group work.

2. Problem-solving classes with a special emphasis on issues that appear in professional practice, as well as those requiring compliance with current legislation. At least once a week, problems are set as an activity to be resolved in small informal groups (with three or four members) formed during the class, to last approximately 10-20 min. Some more complex problems are also set that require research and consultation, (such as the internet and tutorials, among others) solved outside normal class time, and for which they also receive guidance from the teaching staff.

3. Laboratory practice carried out in groups of around 25 , in which students come into contact with the experimental techniques for characterizing material properties and the manufacturing processes of some, such as concrete. They also experiment with the phenomena of the mechanical behavior of the materials studied in the subject. For subsequent courses, we intend to reduce gradually the number of students in the laboratory groups to make them more productive and bring students closer to construction and building materials practice, beginning with concrete dosage, manufacturing and testing. For students who do not have practice on a given day, there would be a class with different activities, such as workshops and technical videos illustrating the knowledge taught in theory classes.

4. Student group workshops. As a novelty, open group work of a certain complexity is set for certain relevant topics on construction and building materials to be studied in depth. Students have to carry out this work outside the class over 3 months (from halfway through the first term) and then present it in public. To help with the task, three student group work sessions are organized in the classroom for the groups to prepare (with the help of a tutor) the work to be completed. The students discuss more openly when they are among themselves, and learn to argue their points of view or proposals better, than when they are with the tutor.

5. Tutorials, to monitor the progress of individual student work, answer questions and correct the problems set, which is of significant importance for group work. Before handing in assignments, the students must meet in their group, reflect on the topic, seek additional information and decide what they are going to do, why they are going to do it, and how they are going to do it. At the start of the work, they discuss their ideas with their tutor, express doubts and any possible alternatives, which all in turn helps decision making. To this end, tutorials with the tutor are organized outside class time.

6. Conferences, given by professionals of renowned prestige on contemporary construction and building materials-related topics: new materials, recycling materials, and singular applications, among others.

7. Practice trips lasting 2 days are organized in coordination with other level two subjects. As part of this activity, students visit a construction site, often for the first time, something which becomes a highly satisfactory experience for them.

The average distribution of time spent by students on the activities, derived from the questionnaire completed by students at the end of course, is shown in Table 4. From these estimates, we 
Table 4. Percentage of Time in Developing the Activities of Construction and Building Materials

\begin{tabular}{lc}
\hline Activities & $\begin{array}{c}\text { Average percentage of time } \\
(\mathrm{h})\end{array}$ \\
\hline Class & $\begin{array}{c}\text { Over a mean time of } 120 \\
\text { Master classes (lectures) }\end{array}$ \\
Problem-solving classes & 60 \\
Laboratory practice & 15 \\
Student group workshops & 10 \\
Tutorials & 10 \\
Conferences & 4 \\
Outside class & 1 \\
Study of the theoretical contents & 60 \\
Students group work & 12 \\
Student individual work & 16 \\
Tutorials & 5 \\
Exam preparation & 5 \\
Practice trip & 2 \\
\hline
\end{tabular}

can deduce that the time devoted to the subject outside class for the proposed new activities increases on average by about $84 \mathrm{~h}$. Nevertheless, there have been no complaints received from another subject of negative side effects; in addition, the increment of time devoted by students to Construction and Building Materials is compensated for by the improvement of the results in the subject.

Finally, it cannot be sufficiently emphasized that in these times it is essential that information technology be included in university teaching. For this reason, during the 2007-2008 academic year, the moodle platform was introduced to include teaching material from the subject and open up the possibility of distancelearning tutorials to eliminate the time lost in unnecessary journeys. These improvements, which lead to easier access to tutors and different parts and sources of the subject through the Web, began to enhance self-study, monitoring, and self-assessment. This action was well rated by students; in particular, the selfassessment questionnaires set were widely used to prepare for examinations. Therefore, we aim to reinforce this in the coming years and continue working along these lines to include new activities on the worldwide Web.

\section{Results}

In order to carry out self-assessment of the quality of the changes introduced in the subject of Construction and Building Materials, the opinion of students was collected on the one hand, in a questionnaire we prepared that was completed at the end of the course, and on the other hand, in the general survey performed by our school in all subjects, as well as through personal interviews held with students in tutorials. The opinions of teachers have been included in monthly meetings held during the course, organized to discuss the progress of the subject and share experiences. Finally, as objective data, statistics have also been recorded of the grades of students in the subject. The percentage of students who answered the questionnaires, formulated to collect their opinions on the subject, was $48 \%$. In the case of the survey carried out at the school, the participation was a considerably lower $16 \%$.

Having applied the improvements in methodology and assessment described in the section "Using Cooperative Learning" during the last three academic years, we have been able to note that
Table 5. Distribution of Student Motivation at the End of the Course

\begin{tabular}{lc}
\hline Student motivation & Average percentage \\
\hline Simply to gain a pass grade & 10 \\
To acquire useful knowledge for the future & 84 \\
To go more deeply into the knowledge & 6 \\
\hline
\end{tabular}

the majority of students have reached a higher level of motivation than that required simply to gain a pass grade. This is reflected in the data in Table 5, which contains the mean values taken from the questionnaires conducted among students at the end of the last two academic periods, 2007-2008 and 2008-2009. Bearing in mind that student satisfaction among those included at the highest level of interest is fairly complex, we consider the percentage shown in the surveys to be reasonably satisfactory.

It can be said that there has been a positive attitude among students and an increase in those showing constancy in going on to higher levels in the subject area. Attendance at lectures has gradually increased up to the current levels of around $78 \%$, a figure that reaches $82 \%$ if we take the percentage of students who have taken part in some of the activities suggested in the subject.

Regarding the number of pass grades, it may be said that there has been a noticeable rise during the last three academic years. For comparison, data on students registered on the Construction and Building Materials module in the last 9 years, from 2000 2001 up to the present, has been used to verify the influence of the use of new methodologies and assessment methods on those achieving pass grades and the number of candidates, since this is data that exist in the records. Fig. 2 shows the percentage of students that passed the subject in each convocation during these years. With this information, in the years before the introduction of the changes (2006-2007), an average number of passes is calculated, giving a result of $46 \%$ for the students enrolled. In particular, in the case of the year prior to 2006-2007, in the academic year 2005-2006, the number of passes was $52 \%$. Since 2006-2007, these figures have risen to a mean value of $75 \%$, a figure which if applied to the number of candidates sitting at least one midterm examination reaches $79 \%$. On each course, the subject can be sat in convocations in three different months: the ordinary convocation in June, and two extraordinary examinations (resitting in February and in September). It is worth noting that a large majority ( $90 \%$ of students) who pass each year do so in the June sitting, and therefore do not perform any special final examination. Specifically, $87 \%$ of students who pass the course do so through continuous assessment, without having to perform any regular final examination in June (see Fig. 2 for details).

These figures reveal that for the time being, the results are vastly encouraging, given that the percentage of pass grades shows a notable rise. It should also be noted that most of the students who passed had undergone continuous assessment. Therefore, it can be said that the increased workload of students is offset by the higher percentage of success in the subject.

Table 6 shows the average of the results obtained in the questionnaires conducted concerning the questions related to the methodology followed. Students were asked to give a score from 1 to 10 . The results were satisfactory, although we feel there remains some area for improvement, which we intend to achieve by making certain adjustments to future courses.

\section{Conclusions}

This paper sets out the introduction of new teaching-learning techniques as a supplement to traditional methodologies for 


\section{Students that pass the subject in each convocation}

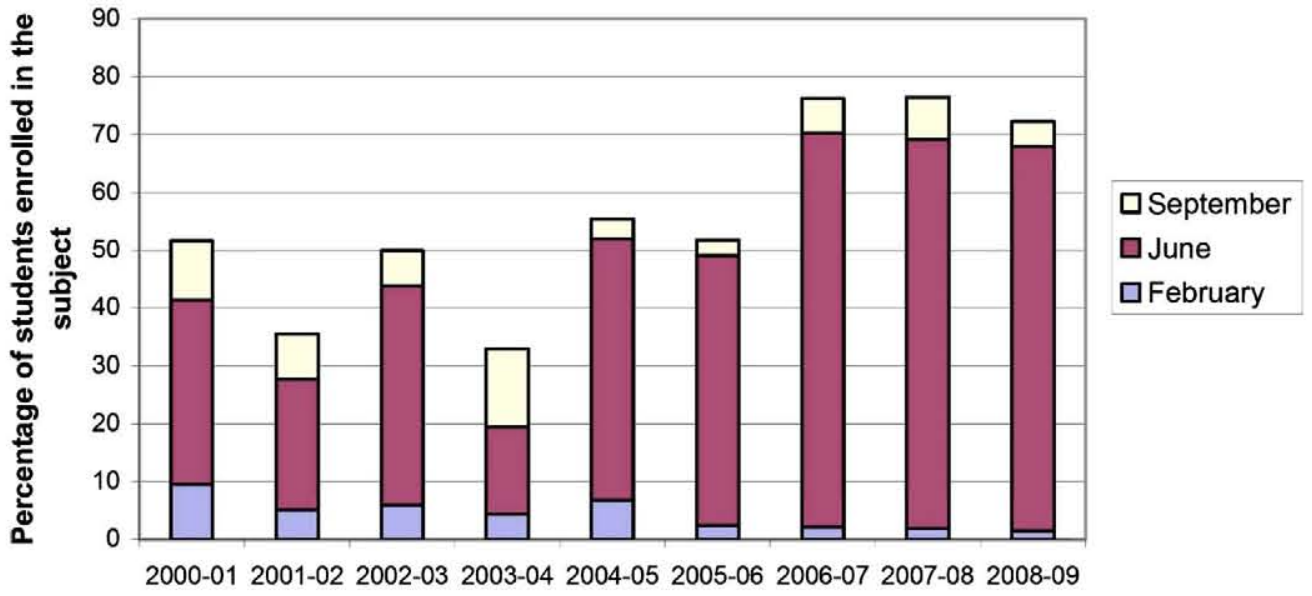

Academic year

Every academic year the subject can be passed in three convocations, in ordinary convocation in June, or in two extraordinary examinations: in February to grade repetition, or in September.

Fig. 2. Percentage of students that pass the subject each year in each convocation

teaching Construction and Building Materials and to improve the training of future civil engineers. With these changes, we hope to address the current demands for the education of civil engineers and at the same time drive student motivation for the subject. In addition, this new way of teaching brings the subject more in line with the new directives laid down in Europe.

Using cooperative learning gives students more opportunities to learn, keeps up motivation, and drives work in the subject. This active teaching technique has many benefits: it encourages longterm student learning, enhances communication skills, develops a capacity for teamwork, promotes critical reasoning and the ability for synthesis and analysis, increases student motivation, and improves the technological training required for their future work. Performing open group work also teaches students to search, manage, and transfer information. Another major change worth underlining is the production of teaching material for the worldwide web. This action has led to student-subject and studentteacher interaction using the computer network with a clear orientation toward self-study in the subject and prior selfassessment. Besides, the quantitative results have been improved due to the fact that the percentage of students that pass the subject has been increased to $29 \%$ on average, and also the percentage that pass in the first convocation has risen to $34 \%$ on average, in comparison with the mean value of the years prior to 2006-2007 in the last decade. This percentage represents an increment of

Table 6. Student Opinion of the Learning Experience (on Completion of the Course)

\begin{tabular}{lc}
\hline Questions asked & Mark \\
\hline $\begin{array}{l}\text { New teaching methods (group work, cooperative problem } \\
\text { solving, regular tutorials, among others) help in learning } \\
\text { the subject }\end{array}$ & 7.7 \\
$\begin{array}{l}\text { Working on problems in a group helps them to be } \\
\text { understood and solved }\end{array}$ & 7.5 \\
$\begin{array}{l}\text { The teacher has motivated students to learn the subject } \\
\text { In general, the subject has satisfied your expectations }\end{array}$ & 7.3 \\
\hline
\end{tabular}

$100 \%$ on average (see Fig. 2 for details). Finally, it is worth noting that $87 \%$ of students who pass the subject every year do so through continuous assessment, without having to perform any final examination.

The general opinion, of both teachers and students from the questionnaires conducted is that, in spite of initial difficulties, our experience has been highly positive. The downside to these innovations in methodology is undoubtedly that the teaching staff need to devote more time to their teaching, which means a considerable increase in their teaching workload (particularly group work preparation, organized tutorials, reading and assessing reports), as well as greater student involvement in their own learning.

\section{Acknowledgments}

The writers gratefully acknowledge the financial support for the innovations introduced in the teaching methods provided by the Universidad Politécnica de Madrid under three annual grants (Grant Nos. IE060415013, IE070415094, and IE080415103) for Educational Innovation.

\section{References}

Alexander, P. A., Murphy, P. K., and Woods, B. S. (1996). "Of saqualls and fathoms: Navigating the seas of educational innovation." Educ. Res., 25(3), 31-36.

Aparicio, A. C., and Ruiz-Terán, A. M. (2007). "Tradition and innovation in teaching structural design in civil engineering." J. Profl. Issues Eng. Educ. Pract., 133(4), 340-349.

Covington, M. V. (2000). "Goal theory, motivation and school achievement: An integrative review." Annu. Rev. Psychol., 51, 171-200.

Elshorbagy, A., and Schonwetter, D. J. (2002). "Engineer morphing: Bridging the gap between classroom teaching and the engineering profession." Int. J. Eng. Educ., 18(3), 295-300.

European Ministers of Education. (1999). "The Bologna declaration of 19 
June 1999." Joint declaration of the European Ministers of Education, 〈http://www.bologna-berlin2003.de/pdf/bologna_declaration.pdf $\rangle$ (Jan. 14, 2006).

European Ministers of Education. (2001). "Towards the European higher education area." Joint declaration of the European Ministers of Education, 〈http://www.bologna-berlin2003.de/pdf/Prague_communiqu Theta.pdf $\rangle$ (Jan. 14, 2006).

Fólder, R. M. (1996). "The warm winds of change." Chem. Eng. Educ., $30(1), 34-35$.

Gálvez, J. C. (2003). Teaching project of construction and building materials, Civil Engineering School, Universidad Politécnica de Madrid, Madrid, Spain (in Spanish).

Johnson, P. A. (1999). "Problem-based, cooperative learning in the engineering clashroom." J. Profl. Issues Eng. Educ. Pract., 125(1), 8-11.

Kelly, W. E. (2008). "General education for civil engineers: Sustainable development." J. Profl. Issues Eng. Educ. Pract., 134(1), 75-83.

Martínez Montes, G., Rubio, M. C., Moreno, B., and Ordóñez, J. (2007). "Final project teaching in higher education within civil engineering: New perspective." J. Profl. Issues Eng. Educ. Pract., 133(2), 94-98.

Quinn, K. A., and Albano, L. D. (2008). "Problem-based learning in structural engineering education." J. Profl. Issues Eng. Educ. Pract., 134(4), 329-334.

Ruiz, G., Gálvez, J. C., Benítez, J. M., Olivares, M. A., and Reyes, E. (2001). "Towards a scientific-technological approach to the teaching of structural concrete as a construction material." Proc., 1st ACHE Conf. on the Teaching of Structural Concrete, Structural Concrete Scientific-Technical Association (ACHE), Madrid, Spain, 265-270 (in Spanish).

Ryan, R. M., and Deci, E. L. (2000). "Self-determination theory and the facilitation of intrinsic motivation, social development and well being." Am. Psychol., 55(1), 68-78.

Salazar, J. M. (2003). "Knowledge management. Origin and organizational implications." Proc., ESINE Forum, Structural Centre for Technical Business Studies, Madrid, Spain (in Spanish).

Sánchez, J. A. (2007). "Teamwork-centred techniques." Course: Alternative techniques for university teaching, Universidad Politécnica de Madrid, Madrid, Spain (in Spanish).

Stevens, R. J. (2004). "Why do educational innovations come and go? What do we know? What can we do?" Teach. Teach. Educ., 20(4), 389-396.

Tapia, J. A. (2007). "Motivation for learning and promoting student interest." Course: How can we motivate students? Motivation for learning and promoting student interest, Universidad Politécnica de Madrid, Madrid, Spain (in Spanish).

Universidad Politécnica de Madrid. (2006). "Teaching aims and programmes." 〈http://www.caminos.upm.es/) (Jan. 20, 2006) (in Spanish). 